\title{
Substance Flow Analysis of Phosphorous in China
}

\author{
Bing Li, Irina Boiarkina, Brent Young, and Wei Yu
}

\begin{abstract}
Phosphorous is an essential natural resource that is projected to run out rapidly. Environmental pollution and resource scarcity pressures require the development of a phosphorous management system in China. One of the fundamental steps to achieve this is to understand the way that phosphorous flows throughout the country. It helps to find out the current phosphorous utilization conditions and provide reliable evidence for both technology and strategy development. Based on these reasons, substance flow analysis of phosphorous was thus conducted to investigate phosphorous flow types and quantify stream values for China. The result indicates that phosphate rock resources in china will run out within 35 years at the current consumption rate, which indicates the urgency of phosphorous recovery. The substance flow analysis will also provide a guide for efficient recovery schemes design in future work. Overall, with a phosphorous crisis approaching in China, it is suggested that work be carried out into phosphorous recovery techniques and management policies.
\end{abstract}

Index Terms-Phosphorous crisis, substance flow analysis, environment management.

\section{INTRODUCTION}

Phosphorous $(\mathrm{P})$ is an essential element in biological organisms and food production. Most of the phosphorous used is sourced from mined phosphate rock, a non-renewable resource with no feasible substitute. Phosphorous fertilizer application is of great importance for plant growth in agriculture and horticulture -it provides and replenishes the required plant nutrients. However, overuse of fertilizer has resulted in nutrient imbalances within local ecosystems, enriching phosphorous concentration in water environments and leading to environmental problems such as red tide and eutrophication [1]. By 2010, more than $90 \%$ of the mined phosphate rock was used for fertilizer production [2]-[4], a demand driven by population growth via food requirements. It is estimated that the world population will reach nine billion by around 2050 [5], putting more pressure on the food supply system, and thus an increase in phosphate rock consumption. However, the world phosphate rock reserve is estimated to run out within the next 70-140 years [6]-[8], especially with the current low phosphorous utilization efficiency- nearly $90 \%$ of phosphorous is lost to the environment after primary consumption [9]. Thus, it is necessary to develop a deep understanding of how phosphate flows within society and control these environmental and

Manuscript received March 19, 2014; revised May 27, 2014

Bing Li, Irina Boiarkina, Brent Young, and Wei Yu are with the University of Auckland, Auckland, 1010 New Zealand (e-mail: bli964@aucklanduni.ac.nz, b.young@aucklanduni.ac.nz,w.yu@aucklanduni.ac.nz). resource risks.

China is one of the main phosphate rock producers and consumers in the world with estimated phosphate rock reserves of around 370,000 million tons in 2013. As shown in Fig. 1 (a), estimated phosphate rock reserves in China decreased significantly during the last ten years, whereas the amount of rock mined has been doubled. When comparing historical data from developed countries (Fig. 1 (b)), China is still in the early stage of phosphorous fertilizer consumption such as developed countries (USA) in the period 1960 to 1970. Thus, phosphorous fertilizer usage in China will increase in the next decade [10]. As a result, the phosphate rock resource will be quickly depleted [11], [12]. Based on these reasons, it is important to investigate phosphorous flows and the utilization efficiency in China to address both the environmental and resource scarcity problems. A key first step to deal with this crisis is to conduct a substance flow analysis (SFA), which can provide fundamental information for advanced nutrient management, as well as promoting the development of a sustainable society.
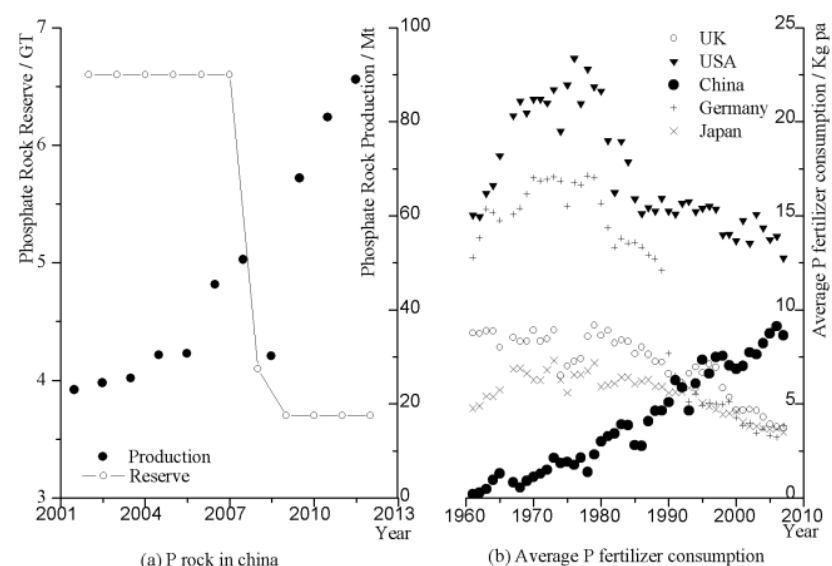

Fig. 1. Phosphorous utilization in different countries (Dara: USGS, 2014; Gapminder, 2014).

Country wide SFA for phosphorous has already been carried out for the USA [13], Japan [14], UK [15], France [16], Australia [17] and Finland [18]. However, these analyses are country specific, based on different economic and societal structures and thus not directly translatable to China. Phosphorous flow in China has been carried out by Chen [19] and Gao [20]. However, these works only focus on agriculture and with the rapid growth being experienced in china, the data has aged quickly. At the same time, a lack of systematic data analysis has therefore failed to provide an alternative method to validate data obtained from literature. It is for these reasons that detailed studies, investigating the influence of current economic and social organizations on phosphorous cycles nationwide are still required. STAN 2.5 developed by Vienna University of Technology was used to 
build the phosphorous flow system and calculate unknown variables in the system. A stock balance sheet was built to check the accuracy of the data utilized, and data uncertainty and validation was considered to improve the reliability of the system. These results were then analyzed to explain the current situation of phosphorous utilization in China.

\section{METHODS}

In this paper, a SFA focusing on phosphorous in China is conducted, irrespective of what form it may appear in [21]. To avoid confusion, all phosphorous flows and stocks are measured in thousands of tons of elemental phosphorous if not specified. This paper concentrates on phosphorous flows in mainland China. Marine environments far from the land area are thus ignored. The main phosphorous flow types are identified based on primary import and export data from governmental reports [22]. A base year of 2012 was chosen to represent the phosphorous quantity sourced from different documents, as the largest amount of data was available for 2012. Data from other years was modified and reconciled to improve the accuracy. This is thus a statistical model and annual variations from different industry sectors might influence the result. However, the analysis is still able to illustrate the basic phosphorous flow situation due to the consistency of economic activity.

Phosphorous flows in China can be divided into three parts: inputs (labeled as 'I' in Fig. 2), outputs (labeled as 'E' in Fig. 2) and domestic consumption (labeled as 'F.W, WB' in Fig. 2). Based on previous reports and the main commodities consumed in China [22] - domestic phosphorous flow can be divided into three subsystems: agriculture, industry and waste treatment. To simplify the system, phosphorous flows in the food processing industry are listed separately. This is because nearly $90 \%$ of the mined phosphorous is applied as fertilizer worldwide [2] and food processing is one of the largest economic industries in China. STAN 2.5 was utilized for phosphorous flow system design and mass balance calculations. This program is designed to perform material flow analysis according to the Austrian standard ÖNorm S 2096 (Material flow analysis Application in waste management). After building a graphical model with predefined components (such as processes, flows, system boundary, and text fields), known data (mass flows, stocks, concentrations, and transfer coefficients) were entered to calculate unknown quantities. All flows can be displayed Sankey-style, which means the width of a flow is proportional to its value. Microsoft Excel was used as the interface for data import and export.

The accuracy of the study depends on the data used for calculations, and thus the data was sourced from multiple and varied sources where possible. Most of the data collected were from the following sources: the National Bureau of Statistics of China, the Ministry of Land and Resources of China and U.S. Geological Survey published reports and research papers. Phosphorous quantities in each flow were quantified by multiplying the amount of the commodity consumed with the respective phosphorous concentration (shown in Eqn 1), when the value was not given directly in the literature.

$$
P=P_{i} \times C_{i}
$$

where, $P_{i}$ is the percentage of phosphorous in flow $i, C_{i}$ is the amount consumed of flow $i$, and $i$ represents different types of flow. If one flow is required to be calculated from two or more sources of unspecified data, it can be quantified as,

$$
P=\sum\left(P_{i} \times C_{i}\right)
$$

For each stock, accumulation of phosphorous (A) is the difference between the amount of phosphorous flowing in and flowing out, namely,

$$
A=P_{\text {in }}-P_{\text {out }}
$$

Data that is currently not available was calculated based on the system mass balance equations in Stan 2.5. However, the software defaults to no accumulation in any process, whereas some accumulation may occur in the systems, e.g., on agricultural land where the phosphorous concentration may increase over time. Thus, we first conducted an agricultural analysis (agricultural land, food, feed and animals) using data obtained from literature to calculate the phosphorous accumulated in the soil. This value was then used to calibrate the negative value obtained when conducting calculations within the whole system. These values are shown in the system flow San-key diagram in Fig. 2.

Despite our efforts to balance and harmonize the information from these disparate data sources, the data applied are subject to varying degrees of uncertainty. Original results were cross checked to ensure the accuracy during the analysis. Most of the data obtained share at least two methods of calculation, with similar results confirming the accuracy of the data. Average values for each flow were then used to represent the real value of each phosphorous flow in the year 2012. To make the SFA result more reliable, a method was developed by other researchers to calculate the uncertainties, in which the uncertainties usually cannot be analyzed by traditional statistical methods [18], [23]. This method was applied by Cooper and Carliell-Marquet, [15], for phosphorous SFA in the UK, and ameliorated over SFAs where uncertainty was taken account of in the balance for some or all of the data. It analyses uncertainty levels from various data sources, such as official statistics and results from journal papers, and applies intervals to each level [15] The uncertainty intervals of the different data sources are

\begin{tabular}{|c|c|c|c|}
\hline & Interval & Source information & Example \\
\hline 1 & $\begin{array}{l}\times / \div \\
1.05\end{array}$ & China official statics report & $\begin{array}{c}\text { China } \\
\text { livestock } \\
\text { census }\end{array}$ \\
\hline 2 & $\times / \div 1.1$ & $\begin{array}{l}\text { Published data with } \\
\text { calculation method }\end{array}$ & $\begin{array}{l}\text { Annual } \\
\text { human P } \\
\text { intake }\end{array}$ \\
\hline 3 & $\times / \div 1.2$ & $\begin{array}{l}\text { Official statics scale up to } \\
\text { china scale }\end{array}$ & $\begin{array}{l}\mathrm{P} \text { in WWTP } \\
\text { effluent }\end{array}$ \\
\hline 4 & $\begin{array}{l}\times / \div \\
1.33\end{array}$ & $\begin{array}{l}\text { Literature without reference or } \\
\text { method }\end{array}$ & $\begin{array}{c}\text { Domestic } \\
\text { food } \\
\text { consumption }\end{array}$ \\
\hline
\end{tabular}
listed in Table I.

TABLE I: UNCERTAINTY INTERVALS

The uncertainty range of each flow is determined on the 
basis of literature information and is propagated during the system calculation [23]. For example, if the number of cows is 1000 , and the uncertainty factor of the number of cows is $\times / 1.05$, the uncertainty range is $1000 / 1.05=952$ and $1000 \times$ $1.1=1050$

\section{RESUlTS AND DISCUSSION}

The phosphorous substance flow analysis for China is shown in Fig. 2. A mass balance of each stock is summarized in Table II, where the data uncertainty of each flow is also shown based on the method provided and then propagated during the calculation.

As shown in Table II, variation means the quotient between accumulation and the input of the stock. Most of the variations are under $10 \%$ and all are within the uncertainty level of the stock (except 'agricultural land'). Therefore, the value of every phosphorous flow is in good agreement with each other and thus is reliable. The variation in agricultural land is $38 \%$.

The reason is a significant amount of phosphorous applied accumulates in the soil [24], which is a major loss during phosphorous utilization [9]. The variation in the non-food sector is around $10 \%$, and this is because the phosphate rock exports of $41.4 \mathrm{kt}$ are also included in the calculation, but are not sourced from agricultural land. After excluding the phosphate rock from the calculation, the variation in the non-food sector is then estimated to be $0.03 \%$, which is very low.

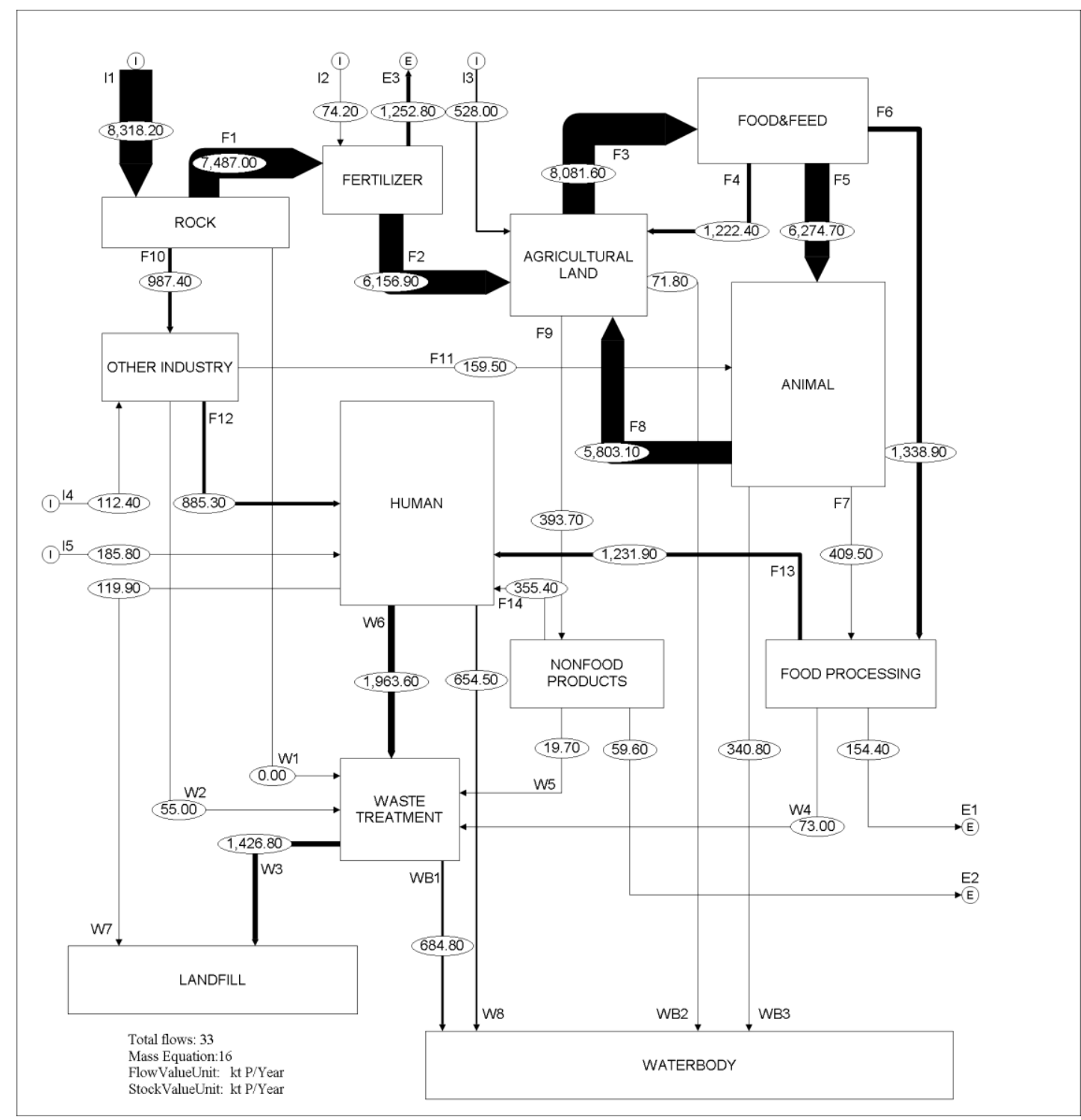

I1: DOMESTIC MINING

I2: FERTILIZER IMPORT

I3: NATURE PRECIPATION

I4: MINERAL IMPORT

I5: FOOD IMPORT

F1:P PRODUCTION

F2:P APPLICATION

F3:PLANT UPTAKE

F4:PLANT RESIDUAL
F5: LIVESTOCK GRAZING F6:CROP PRODUCTION F7: LIVESTOCK PRODUCT F8: LIVESTOCK MANURE F9: OTHER PRODUCTS F10: P ROCK OTHER F11: LIVESTOCK FEED F12: OTHER INDUSTRY F13: DOMESTIC FOOD
F14: DOMESTIC OTHER W1: FERTILIZER LOSS W2: OTHER LOSS W3: WASTE LANDFILL W4: FOOD LOSS W5: NONFOOD LOSS W6: HUMAN WASTE W7: SLUDGE LANDFILL W8: DIRECT LOSS
WB1: WWYP EFFLUENT WB2: CROP LAND LOST WB3: LIVESTOCK LOST E1: FOOD EXPORT E2: OTHER EXPORT E3: FERTIER EXPORTED

Fig. 2. Substance flow analysis of phosphorous flow in China (Stan 2.5). 
TABLE II: PHOSPHOROUS BALANCE IN DIFFERENT SECTORS

\begin{tabular}{ccccc}
\hline \hline Stock name & In & Out & $\begin{array}{c}\text { Difference } \\
(\%)\end{array}$ & $\begin{array}{c}\text { Uncertainty } \\
(\%)\end{array}$ \\
\hline Rock & 8318 & 8474 & 2 & {$[ \pm 3660]$} \\
Fertilizer & 7561 & 7410 & 2 & {$[ \pm 3327]$} \\
Agriculture & 13710 & 8547 & 38 & {$[ \pm 3565]$} \\
Food\& Feed & 8081 & 8836 & 9 & {$[ \pm 4364]$} \\
Animal & 6434 & 6553 & 2 & {$[ \pm 3475]$} \\
Food & 1748 & 1459 & 17 & {$[ \pm 372]$} \\
Non-food & 393 & 435 & 10 & {$[ \pm 61]$} \\
Human & 2658 & 2738 & 3 & {$[ \pm 1053]$} \\
Other & 1099 & 1100 & 0 & {$[ \pm 171]$} \\
Waste & 2084 & 2111 & 3 & {$[ \pm 688]$} \\
Landfill & 1547 & 0 & N/A & N/A \\
Water body & 2052 & 0 & N/A & N/A \\
\hline \hline
\end{tabular}

Variation in food processing is around $16.5 \%$, this is because the volume of domestic food consumption is estimated from the rural food consumption structure and thus the real value should be slightly larger when applied nationwide. This difference is ignored here because of a lack of data. Based on the volume of different phosphorous streams, a breakdown of the overall phosphorous inputs and outputs in China is shown in Fig. 3 (in units of thousands tons of elemental phosphorous), where percentage means the proportion of different phosphorous flow in the total input and output flows.

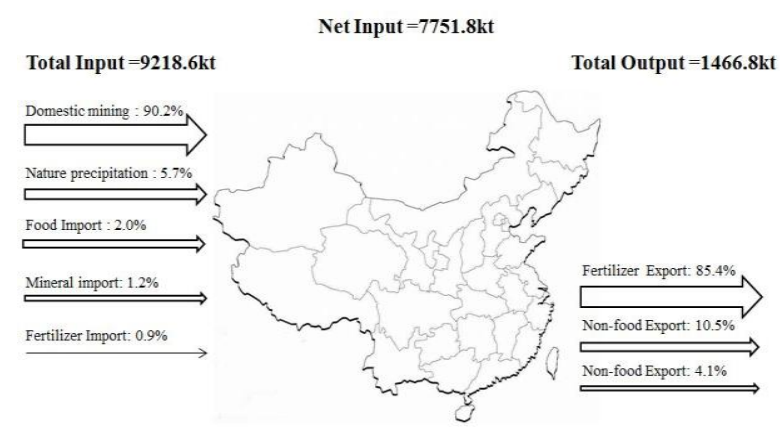

Fig. 3. $\mathrm{P}$ input and output in China.

As described, the total phosphorous input to China is 9219 $\mathrm{kt}$, and the majority comes from phosphate rock mining; total output is $1467 \mathrm{kt}$, mainly in the form of fertilizer. This led to a phosphorous accumulation of $7752 \mathrm{kt}$ in 2012. Excluding phosphorous leachate from soil to water bodies, $20 \%$ of the waste phosphorus ends up in landfills, $27 \%$ runs off into water bodies and the remainder is left in the soil. These results indicate that the phosphorous flow system in China is self-sufficient, with a significant amount of phosphorous lost to the environment after primary usage. To better understand the phosphorous utilization efficiency in agriculture, a detailed soil phosphorous mass balance sheet was established below.

TABLE III: SoIL PHOSPHOROUS MASS BALANCE SHEET (KT P/YEAR)

\begin{tabular}{cccc}
\hline \hline & Inputs & & Outputs \\
\hline Fertilizer & 6685 & Crops/forage & 7614 \\
Manure & 5803 & Other products & 394 \\
Plant residue & 1222 & Surface runoff & 413 \\
Total in & 13710 & Total out & 8420 \\
\hline \hline
\end{tabular}

In the balance sheet, soil phosphorous leaching is not considered. It indicates that $5291 \mathrm{kt}$ phosphorous is stabilized in the agricultural land, and this is nearly $43 \%$ of the total fertilizer applied (both chemical fertilizer and animal manure). Agricultural land took up $56 \%$ of the total national land area in 2012 [24], which suggests an average phosphorous input of $26 \mathrm{~kg} \mathrm{P} / \mathrm{ha}$ and average phosphorous output of $16 \mathrm{~kg} \mathrm{P} / \mathrm{ha}$. Thus, the phosphorous utilization efficiency in agriculture is $62 \%$. It should be noted that this kind of accumulation is likely to be magnified in intensive livestock farms, due to the challenges posed by transport and effective phosphorous distribution.

As can be seen from the above analysis, the phosphorous rock resource in China is under risk. The total phosphorous rock reserves in terms of elemental phosphorous is around 285 million tons when considering the average $\mathrm{P}_{2} \mathrm{O}_{5}$ content in China's phosphate rock to be $17.5 \%$ [25]. The phosphorous mined in 2012 was around 8.35 million tons [26] in the form of elemental phosphorous, which means the phosphorous resources will deplete in 35 years without proper management. Major environmental problems caused by excessive phosphorous application are red tide and eutrophication. The largest contributor of phosphorous loss to water bodies in China is from diffuse source run off, estimated to be around $1067 \mathrm{kt}$ in 2012. This number would be larger when considering the phosphorous leaching from agricultural land and landfill sites. Total phosphorous loss from point sources is estimated to be $685 \mathrm{kt}$. Therefore, phosphorous pollution from diffuse sources poses greater environmental risk to water bodies in China and thus control strategies should be developed.

\section{CONCLUSION}

A systematic substance flow analysis of phosphorous in China was conducted and revealed different phosphorous flows nationwide for the first time. The phosphorous resources in China are going to be depleted in 35 years under the current consumption structure. Annual phosphorous inputs and outputs in China are $9219 \mathrm{kt}$ and $1467 \mathrm{kt}$ respectively. Analysis shows that agriculture is the most phosphorous-intensive sector with phosphorous utilization efficiency at around $62 \%$ and that a significant amount phosphorous is lost to the environment after primary usage. What is more, it is proved that diffuse sources, rather than point sources pose greater risk for eutrophication in China's water bodies. To achieve higher phosphorous utilization efficiency in China, improving nutrient recovery efficiency and reducing soil phosphorous accumulation is recommended.

\section{REFERENCES}

[1] E. Bennett and J. Elser, "A broken biogeochemical cycle,” Nature, vol. 478, pp. 478-483, Oct. 2011.

[2] R. Rawashdeh and P. Maxwell, "The evolution and prospects of the phosphate industry," Mineral Economics, vol. 24, pp. 15-27, May 2011.

[3] R. W. Scholz and F.W. Wellmer, "Approaching a dynamic view on the availability of mineral resources: What we may learn from the case of phosphorus?" Global Environmental Change, vol. 24, pp. 11-27, Feb. 2012. 
[4] S. J. V. Kauwenbergh, M. Stewar, and R. Mikkelsen, "World reserves of phosphate rock: A dynamic and unfolding story," Better Crops, vol. 97, pp. 18-20, Aug. 2013.

[5] W. Lutz and K. C. Samir, "Dimensions of global population projections: What do we know about future population trends and structures?" Philosophical Transactions of the Royal Society B: Biological Sciences, vol. 365, pp. 2779-2791, Aug. 2010.

[6] C. Kabbe, "The limited resources of phosphorus and how to close the phosphorus cycle," Eco-Efficiency in Industry and Science, vol. 30, pp. 61-273, Dec. 2013

[7] R. W. Scholz et al., "Sustainable use of phosphorus: A finite resource," Science of The Total Environment, vol. 461, pp. 799-803, Sep. 2013

[8] D. Vaccari, "Phosphorus: A looming crisis," Scientific American Magazine, Sustainability, vol. 300, pp. 54-59, June 2009.

[9] D. Cordell, J. O. Drangert, and S. White, "The story of phosphorus: Global food security and food for thought," Global Environmental Change, vol. 19, pp. 292-305, May 2009.

[10] L. Bouwman, K. K. Goldewijk, A. H. W. Beusen, D. P. V. Vuuren, J. Willems, M. C. Rufino, and E. Stehfest, "Exploring global changes in nitrogen and phosphorus cycles in agriculture induced by livestock production over the 1900-2050 period," Proceedings of the National Academy of Sciences, vol. 110, pp. 20882-20887, Dec. 2013.

[11] N. Gilbert, "Environment: The disappearing nutrient," Nature, vol. 461, pp. 716, Oct. 2009.

[12] D. Cordell, M. Jackson, and S. White, "Phosphorus flows through the Australian food system: Identifying intervention points as a roadmap to phosphorus security," Environmental Science \& Policy, vol. 29, pp. 87-102, May 2013.

[13] S. Suh and S. Yee, "Phosphorus use-efficiency of agriculture and food system in the US." Chemosphere, vol. 84, pp. 806-813, Aug. 2011.

[14] K. Y. Matsubae, "A material flow analysis of phosphorus in Japan," Journal of Industrial Ecology, vol. 13, pp. 687-705, Oct. 2009.

[15] J. Cooper and C. Carliell-Marquet, "A substance flow analysis of phosphorus in the UK food production and consumption system,' Resources, Conservation and Recycling, vol. 74, pp. 82-100, May 2013.

[16] K. Senthilkumar, "Conceptual design and quantification of phosphorus flows and balances at the country scale: The case of France," Global Biogeochemical Cycles, vol. 26, Sep. 2012.

[17] D. Coedell and S. White, "Sustainable phosphorus measures: Strategies and technologies for achieving phosphorus security," Agronomy, vol. 3, pp. 86-116, Jan. 2010

[18] R. Antikainen, "Stocks and flows of nitrogen and phosphorus in the Finnish food production and consumption system," Agriculture, Ecosystems \& Environment, vol. 107, pp. 287-305, June 2005.

[19] M. Chen, J. Chen, and F. Sun, "Agricultural phosphorus flow and its environmental impacts in China," Science of the Total Environment, vol. 405, pp. 140-152, Aug. 2008

[20] X. Gao, "Analysis on the current status of utilization of crop straw in China," Journal Huazhong (Central China) Agricultural University, vol. 21, pp. 242-247, Mar. 2001.

[21] T. E. Graedel and B. R. Allenby, Industrial Ecology and Sustainable Engineering, Prentice Hall Upper Saddle River, pp. 151-158, May 2010.

[22] J. Ma, China Statistical Yearbook, China Statistical Press, 2014, pp. 454-531.

[23] J. Hedbrant and L. Sörme, "Data vagueness and uncertainties in urban heavy-metal data collection," Water, Air and Soil Pollution: Focus, vol. 1, pp. 43-53, June 2011.

[24] T. Nagumo, S. Tajima, and A. Yamashita, "Phosphorus balance and soil phosphorus status in paddy rice fields with various fertilizer practices," Plant Production Science, vol. 16, pp. 69-76, Mar. 2013.

[25] World Bank. (Mar 2014). Composition of phosphate rock. [Online], Available: http://data.worldbank.org/indicator/AG.LND.AGRI.ZS
[26] B. Zhu, S. Y. Jiang, J. H. Yang, D. H. Pi, H. F. Ling, and Y. Q. Chen, "Rare earth element and SrNd isotope geochemistry of phosphate nodules from the lower Cambrian Niutitang Formation, NW Hunan Province, South China," Palaeogeography, Palaeoclimatology, Palaeoecology, vol. 398, pp. 132- 143, Mar. 2013.

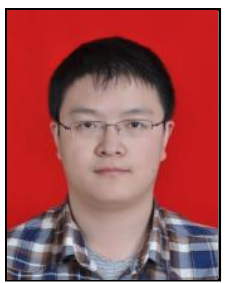

Bing Li obtained his master degree in energy and environment engineering from the University of Sheffield, UK and is now a $\mathrm{PhD}$ candidate from the University of Auckland, New Zealand. He is now working on phosphorous recovery schemes and techniques to provide suggestions and solutions for the coming phosphorous crisis

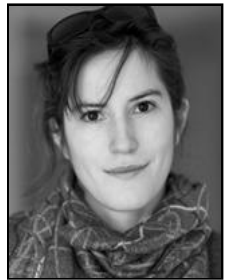

Irina Boiarkine completed her $\mathrm{PhD}$ degree in chemical engineering at the University of Auckland in 2013. Before starting her $\mathrm{PhD}$, she worked as a process engineer at Harrison Grierson Consultants in water treatment plant design and assessment. She is currently employed as a postdoctoral fellow at the University of Auckland, with research interest in the process analytical technology, process modeling, reactor design and dairy and milk powder areas.

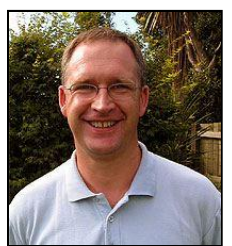

Brent Young is a professor in the Department of Chemical and Materials Engineering at The University of Auckland. He holds the position of the chair in Food Process Engineering and is the director of the Industrial Information and Control Centre. He is also an adjunct professor at the University of Calgary.

$\mathrm{He}$ was previously an associate professor in chemical and petroleum engineering at the University of Calgary from 1998 to 2005 and a lecturer in chemical technology at the University of Technology, Sydney from 1991 to 1998 . He has also held prestigious visiting positions including an NSERC at Calgary in 1995, an Erskine at Canterbury in 2005 and a Gledden at Western Australia in 2009 $\mathrm{He}$ is a chartered engineer and a fellow of the IChemE. His research is centered on the two major areas, process simulation and control, and process design and development particularly the processing of carbonaceous and food substances.

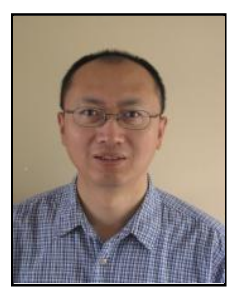

Wei Yu is a lecturer for the Chemical and Materials Engineering Department, the University of Auckland from 2012. He worked as a postdoctoral fellow at Industrial Information and Control Centre $\left(\mathrm{I}^{2} \mathrm{C}^{2)}\right.$ Faculty of Engineering, the University of Auckland, New Zealand from 2008 to 2011 . He received his B.E. degree in 1993 in chemical engineering from Liaoning University of Petroleum and Chemical Technology, Fushun, P.R. China, master degree in 2003 and Ph.D. degree in 2007 in chemical engineering from the Queen's University, Canada. He worked as a process engineer at West Pacific Petrochemical Company, Dalian, P.R. China from 1993 to 1999. His main research interests include control performance assessment, analysis of variance and process control and identification 